The representative office of the ESI Group (France), the internationally acclaimed developer of software for computer modeling, would like to direct your attention to a series of articles prepared for an ongoing section of the journal Metallurgist together with our partner in Russia - the PLM Ural - Delkam-Ural Company Group.

This series will be devoted to the mathematical modeling of production processes at modern industrial plants. In these articles, we will describe examples of the use of software products developed by the ESI Group to solve engineering problems encountered in sheetmetal stamping (including elastic forming and superplastic deformation) and the casting, welding, and heat treatment of metals.

We hope that the material presented in the articles will broaden the potential of mathematical modeling for solving practical engineering problems and will show through practical examples that these software products are an effective tool for saving money and time in manufacturing operations.

\title{
FORMING OF TEE PARTS BY A PROCESS \\ THAT COMBINES DIFFUSION WELDING AND PNEUMOTHERMAL FORMING IN THE SUPERPLASTIC REGIME
}

\author{
A. A. Cheslavskaya, ${ }^{1}$ V. V. Mironenko, ${ }^{1}$ \\ S. A. Bersenev, ${ }^{1}$ and V. V. Kotov ${ }^{2,3}$
}

UDC 621.7.04

An alternative method is described for making tees. The article discusses the main stages in the advanced method, which combines diffusion welding and pneumothermal forming in the superplastic regime. The process of superplastic pneumothermal forming is modeled and calculated results are reported. In the method, pneumothermal forming is preceded by diffusion welding.

Keywords: pneumothermal forming of sheet metal parts, superplastic effect, tubular parts made from sheets.

Parts called "tees" are commonly used in the systems of conduits in aircraft to separate flows of liquid or gas into two flows or to combine two such flows (Fig. 1).

To make such parts, a drop hammer or a rigid die is used to divide a flanged pipe into two symmetrical halves which are then welded. This standard tee-forming technology has several shortcomings:

1) a significant amount of material is lost because of the established tolerances;

2) the finishing operations, involving the stamping and welded of a flanged pipe, are labor-intensive; and

3 ) it is necessary to use several different types of equipment.

\footnotetext{
${ }^{1}$ Irkutsk State Technical University, Irkutsk, Russia.

${ }^{2}$ ESI Group, Russian Office.

${ }^{3}$ Yeltsin Ural Federal University (UrFU), Ekaterinburg, Russia; e-mail: viacheslav.kotov@esi-group.com.
}

Translated from Metallurg, No. 12, pp. 32-34, December, 2012. Original article submitted December 3, 2012. 


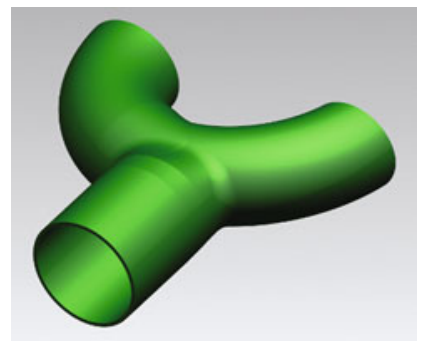

Fig. 1. A part of the tee type.

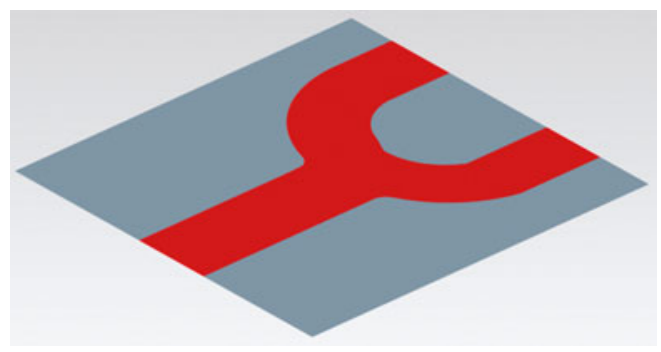

Fig. 2. Region of application of anti-welding coating.

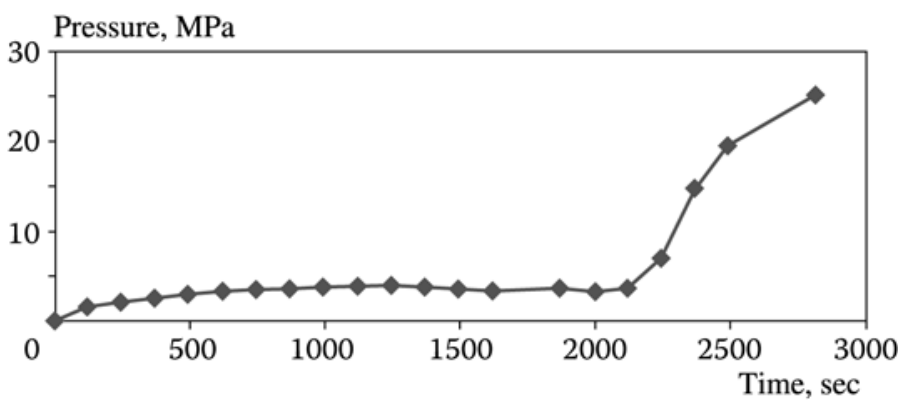

Fig. 3. Graph of the time dependence of pressure obtained from the results of the modeling.

Here, we examine an alternative method of making tees that resolves the above problems - a process that combines diffusion welding with pneumothermal forming in the superplastic regime. The part is made from two sheets, as in the traditional technology. However, the new method employs diffusion welding and the desired final shape is obtained by superplastic forming.

First, a template is used to apply an anti-welding coating to the parts of the semifinished product that are not to be welded, i.e., to the parts that will form the channel of the tee. The prepared semifinished product is then placed in a heated jig for diffusion welding and superplastic forming; pressure is created and maintained for the period of time needed to perform the welding operation.

After the welding has been completed, the jig and the accompanying packet of semifinished products is further heated to the temperature at which it becomes superplastic. Then enough pressure is created inside the cavity that is created in order to allow pneumothermal forming of the part while it is in the superplastic state.

Certain temperature conditions must be established in order to carry out the forming operation, the exact conditions depending on the material of the part and the pressure. The pressure is changed during the process to ensure that the defor- 


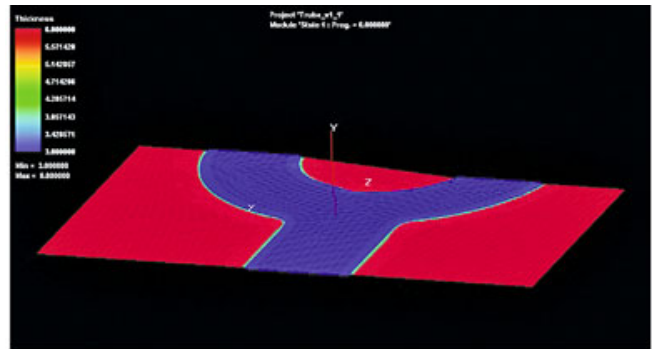

$\tau=0 ; d_{\max }=6 \mathrm{~mm} ; d_{\min }=3 \mathrm{~mm}$

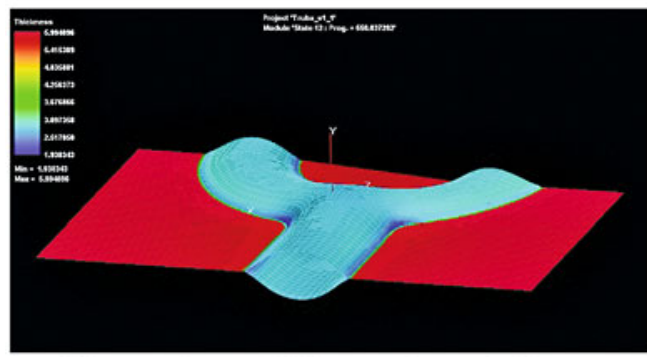

$\tau=550 \mathrm{sec} ; d_{\max }=5.99 \mathrm{~mm} ; d_{\min }=1.93 \mathrm{~mm}$

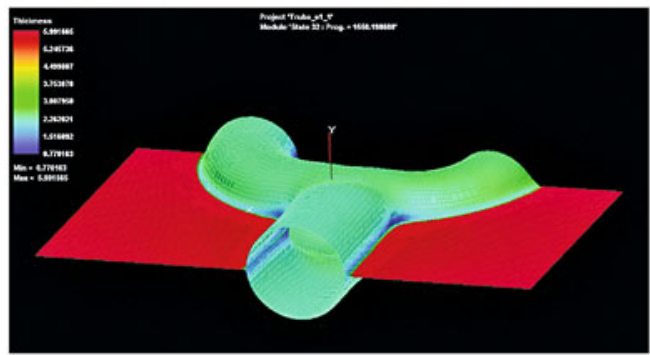

$\tau=1550 \mathrm{sec} ; d_{\max }=5.99 \mathrm{~mm} ; d_{\min }=0.77 \mathrm{~mm}$

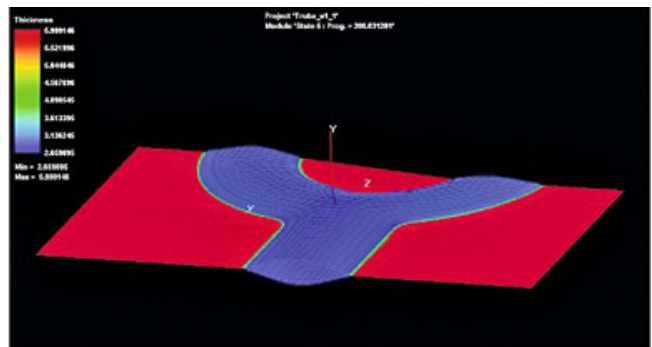

$\tau=200 \mathrm{sec} ; d_{\max }=5.99 \mathrm{~mm} ; d_{\min }=2.65 \mathrm{~mm}$

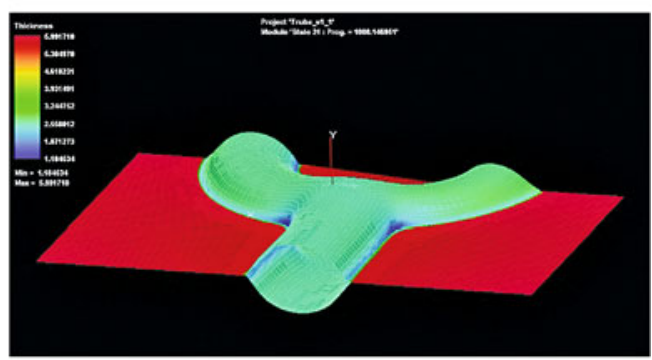

$\tau=1000 \mathrm{sec} ; d_{\max }=6 \mathrm{~mm} ; d_{\min }=1.18 \mathrm{~mm}$

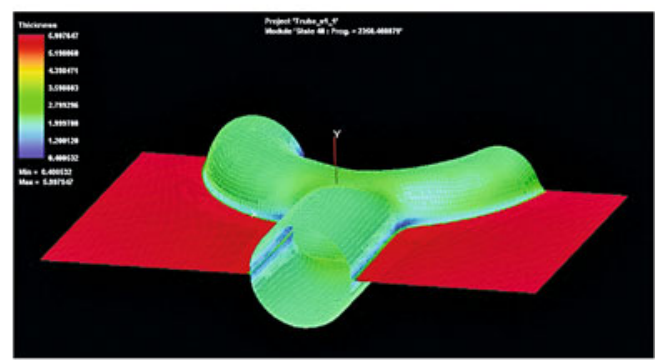

$\tau=2818 \mathrm{sec} ; d_{\max }=5.99 \mathrm{~mm} ; d_{\min }=0.44 \mathrm{~mm}$

Fig. 4. Sequence of stages in the forming operation: $\tau-$ time; $d_{\max }-$ maximum thickness; $d_{\min }-$ minimum thickness.
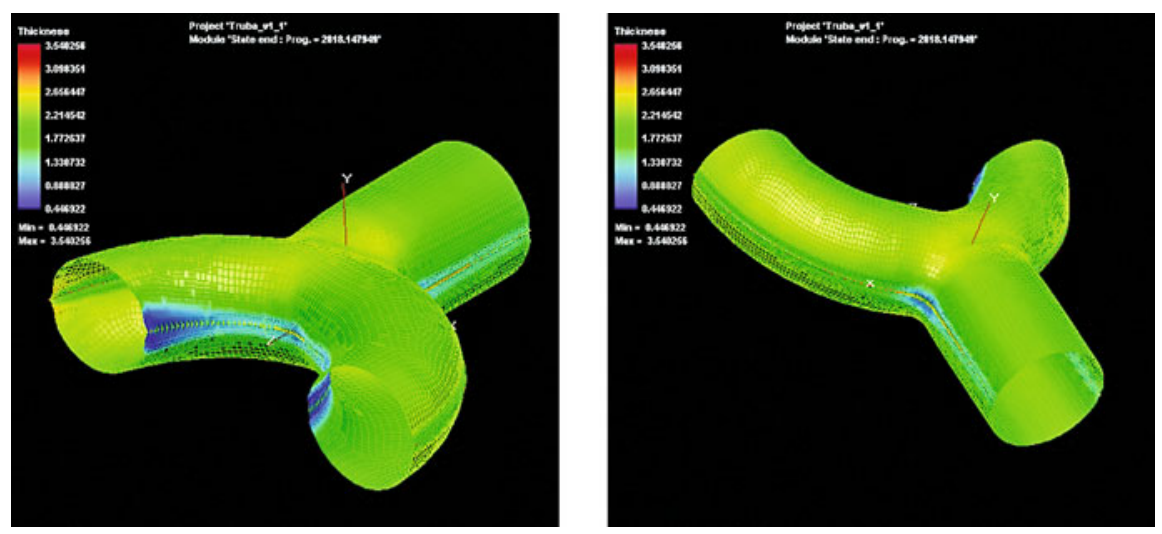

Fig. 5. Thickness distribution in the part: $d_{\max }=3.54 \mathrm{~mm} ; d_{\min }=0.44 \mathrm{~mm}$. 
mation rate remains constant. The parameters that are needed and the character of their change during the process are determined by mathematical modeling.

As an example, let us examine the process of mathematically modeling the fabrication of a tee from two 3-mm-thick sheets of titanium alloy VT20. The diameters of the tubular parts of the tee (see Fig. 1) were as follows in the modeling operation: central part $-30 \mathrm{~mm}$; right branch $-26 \mathrm{~mm}$; left branch $-28 \mathrm{~mm}$.

An anti-welding coating (depicted by the color red in Fig. 2) is applied to both semifinished products.

The coated surfaces of the semifinished products are then positioned face-to-face and the semifinished products are joined together at their ends by electric-arc welding. The welded packet is secured in the above-mentioned jig and placed inside a press for pneumothermal forming in the superplastic regime. During this process, the uncoated parts of the semifinished products undergo diffusion welding at $910^{\circ} \mathrm{C}$ and a pressure of $10 \mathrm{~atm}$ (the diffusion-welded region is depicted by the color blue in Fig. 2).

The parameters for forming in the superplastic regime were determined by modeling the process in the software package PAM-STAMP 2G, which was created by the French company ESI Group. The following simplified model was used in the modeling operation to describe the behavior of the material in the superplastic regime [1]:

$$
\sigma=K \dot{\varepsilon}^{m},
$$

where $K$ is a proportionality factor; $\dot{\varepsilon}$ is the strain rate; $m$ is the strain-hardening modulus; and $\sigma$ is the stress.

The below parameters were used to model material VT20 in the software:

- elastic modulus - $112 \mathrm{GPa}$;

- Poisson's ratio - 0.333;

- density $-4.5 \cdot 10^{-6} \mathrm{~kg} / \mathrm{mm}^{3}$;

- proportionality factor $-0.597488 \mathrm{GPA}$;

- strain rate -0.0016 [2];

- strain-hardening modulus - $0.42[2]$.

The forming operation was performed with allowance only for the reduction in the thickness of the semifinished products. The behavior of the material in the regions where it transitioned from diffusion welding to the presence of an antiwelding coating was accounted for by joining the nodes of the elements in those regions. The behavior of the ends of the semifinished products, where the shaping was done, was accounted for in the model by prohibiting movement of the ends along a normal extending in the ends' direction.

Modeling the process of forming the tee yielded a graph that shows the dependence of the pressure on time and can be used to keep the strain rate constant for a maximum pressure of $25 \mathrm{MPa}$ and a forming time of $2818 \mathrm{sec}$ (Fig. 3).

It is apparent from the modeling that both sheets are formed symmetrically and a whole tee is obtained in a single operation (Fig. 4).

A finished, intact tee is obtained after the metal comprising the allowance is cut off. The geometry of the tee replicates the geometry of the jig as closely as possible, i.e., no further treatment of the tee is needed after forming or welding.

Figure 5 shows the thickness distribution of the part obtained by modeling.

Modeling of the forming operation showed that the use of a technology which combines diffusion welding and pneumothermal forming in the superplastic regime makes it possible to avoid several problems in the production of tees:

1) it eliminates a large number of finishing operations. Use of the technology produces parts that are of the prescribed dimensions and are free of the defects associated with electric-arc welding and formation of the parts of tubes with flanges;

2) springback is also eliminated by pneumothermal forming in the superplastic regime; and

3) use of the technology obviates the need for certain types of equipment. In the case being considered here, all the operations involved in diffusion welding and superplastic pneumothermal forming are performed on a single piece of equipment. 


\section{REFERENCES}

1. E. N. Chumachenko, O. M. Smirnov, and M. A. Tsepin, Superplasticity: Materials, Theory, Technologies [in Russian], Kom Kniga, Moscow (2005).

2. O. M. Smirnov, Metal-Shaping in the State of Superplasticity [in Russian], Mashinostroenie, Moscow (1979). 